\title{
Belief in Just World and Life Satisfaction in Undergraduate Students: Cross Cultural Study in Indonesia and China
}

\author{
Endah Puspita Sari \\ Psychology Study Program, Islamic \\ University of Indonesia, Indonesia \\ endah_puspita_sari@uii.ac.id
}

\author{
Ahmad Zain Fahmi \\ Psychology Study Program, Islamic \\ University of Indonesia, Indonesia \\ ahmadzainfahmi6@gmail.com
}

Muhammad Garlianka

Wangsadikrama

Psychology Study Program, Islamic University of Indonesia, Indonesia wangsadikrama26@gmail.com

\author{
Nadhila Safitri \\ Psychology Study Program, \\ Islamic University of \\ Indonesia, Indonesia \\ nadhila.ns@gmail.com
}

Department of Education Science, Zhoukou Normal University, PRC yifang_2008@।26.com

\author{
Qianqian Lu \\ Department of Education \\ Science, Zhoukou Normal \\ University, PRC \\ 919626852@qq.com
}

\begin{abstract}
The purpose of this research was to compare cross-culturally between belief in just world and life satisfaction among students in China and Indonesia. Subjects in this study were 194 students in China and II 2 students in Indonesia who vary in religion, race, and study field. This research used three scales to collect the data, the Global Belief in Just World Scale, Personal Belief in Just World Scale, and the Satisfaction with Life Scale. The correlation test showed that for Indonesian subject, the strong correlation is between Personal Belief in Just World and Life Satisfaction $(r=0.330, p=0.000)$. And for China subject, the strong correlation is between Personal Belief in Just World and Life Satisfaction $(r=0.412$, $p=$ 0.000 ). From the comparative test, Global Belief in Just World in Indonesia subjects were higher than in China subjects $\left(\eta^{2}=0.066, p=0.000\right)$. A more detailed explanation will be provided in this paper.
\end{abstract}

Keywords: Belief in just world, life satisfaction, undergraduate students, Indonesia, China.

Received 18 January 202I/Accepted 9 March 202I (CAuthor all rights reserved

\section{Introduction}

Life satisfaction is considered as the most important and the most stable component of the Subjective Well-Being (SWB) variable (Kim-Prieto, Diener, Tamir, Scollon, \& Diener, 2005). Life satisfaction or the perception of the quality of life is a broad construct, which leads to the functioning of very "low" to "medium" to "very high" as an indicator of optimal functioning of adolescents (Suldo \& Huebner in Antaramian, Huebner, \& Valois, 2008). Other experts, Pavot \& Diener (1993), state that life satisfaction is a measure of the overall 
life satisfaction of an individual. Furthermore, they explain that the measurement of life satisfaction is not as specific as the measurement of health or financial domains, but it allows individuals to integrate and measure life domains by comparing the criteria they set themselves.

Individuals who have life satisfaction may have a lower risk of suicide (Koivumaa-Honkanen et al., in Pavot \& Diener, 2008). For women, life satisfaction is associated with healthier heart conditions (Matthews et al., in Pavot \& Diener, 2008). Long-term research on life satisfaction in adolescent subjects find that low levels of life satisfaction, conducted in 2007 and 2008 by Huebner et al. (Antaramian et al., 2008) can predict external and internal behavior from experiences of peer victimization. In contrast, Suldo and Huebner (Antaramian et al., 2008) found that adolescents with high life satisfaction show less external behavior after experiencing significant life stressors. Based on research conducted on nonclinical samples, it is found that adolescents with low life satisfaction have an increased risk of showing maladaptive behavior, such as drinking alcohol or engaging in alcohol abuse (Zulliget in Proctor, Linley, \& Maltby, 2009). Suldo and Huebner (Antaramian et al., 2008) further conclude that life satisfaction is seen as a crucial psychological force that can facilitate the adaptive development of individuals.

Based on the stage of educational development, research on life satisfaction at the tertiary level of education is crucial for campus administrators. It is confirmed by Valois et al. (Zhang, Zhao, Lester, \& Zhou, 20l4) that the increased life satisfaction while undergoing college education in college students can reduce the risk of physical illness and mental disorders. Strengthened by preliminary studies summarized by Zhang et al. (2014), they argue that life satisfaction positively relates to higher self-esteem, stronger social support, and better living conditions. They also explain that life satisfaction negatively relates to depression and suicidal ideas.

In cross-cultural research related to life satisfaction variables, Diener and Diener (Pavot \& Diener, 2008) find that research subjects, coming from individualist countries with high life satisfaction scores, have higher self-esteem than research subjects from collectivist countries. Besides, Suh et al. (Pavot \& Diener, 2008) reveal that at the individual level, the 
measurement of life satisfaction closely relates to emotions in individualist culture. In this term, social norms (such as normative values of life satisfaction) are crucial for emotions in predicting life satisfaction in culture-collectivist culture. Another study conducted by Schimmack, et al. (Pavot \& Diener, 2008) compares data from collectively cultured countries (Japan, Mexico, and Ghana) and countries with individualist cultures (Germany and America). They find that the influence of personality on the emotional components of SWB is the same across cultures. However, in terms of life satisfaction, it is moderated by culture. Thus, the assessment of individual life satisfaction can vary depending on the culture that develops in a country.

Lerner and Miller (Lipkus, Dalbert, \& Siegler, 1996) stated that Belief in Just World (BJW) is a theory of justice with a basic premise believing that individuals get what they should get. It is a positive illusion that encourages individuals to see the world as fair, meaningful, and predictable (Lerner \& Miller in Lipkus et al. 1996). Besides, BJW contributes to SWB through the mechanism of increasing someone feelings of competence and control, looking ahead to a positive future (Ellard in Lipkus et al., 1996) or seeing the life situation that individuals live in is a situation that deserves and is lived (Hafer \& Olson in Lipkus et al., 1996). Individuals who have a strong belief in justice can cope adaptively to negative life events. Furthermore, they have a more positive effect than individuals with low BJW (Lipkus et al., 1996). For example, individuals who have a belief in a just world have negative emotions that are less intense, such as angry emotions (Dalbert in Lench \& Chang, 2007).

In several countries, there have been several studies conducted to investigate the relation between Belief in Just World (BJW) with SWB in adolescents and early adults. Among these studies is Correia and Vala's research conducted in Portugal involving adolescents and early adults (Dalbert \& Stoeber, 2006). This study reveals that the stronger the BJW, the more satisfied the research subject will be with the life he lives. In this study, controlling internal belief strengthens the correlation between the two research variables. Another study, conducted by Dzuka and Dalbert with the subject of Slovak adolescents, shows several results (Dalbert \& Stoeber, 2006). They indicate that there is a positive relationship between BJW and life satisfaction, and there is a positive relationship between BJW and positive aspects. This relationship is maintained by controlling for personality dimensions 
(such as extraversion, neuroticism), demographic conditions (gender, unemployment status), and situational factors (personal financial situation). Besides, they also investigate the adaptive relationship between BJW and SWB in three samples of German and Slovak adolescents. The more the subject believes that he lives in a just world, the more satisfied he is with life and the more positive the effect he feels. This relationship is maintained by controlling for larger personality dimensions, such as neuroticism and extraversion.

Considering (Diener, Emmons, Larsen, \& Griffin, 1985) statement saying that the measurement of life satisfaction is not only reliable for subjects in America but also people in all parts of the world, the researcher chooses life satisfaction as the variable in this study. Besides, as studies on life satisfaction are mostly conducted in America and Europe, it convinces the researchers to explore life satisfaction in Indonesian and Chinese people (Chang, Chang, Li, Xi, Liu, \& Zhang, 2019; Chu, Khan, Jahn, \& Kraemer, 2015). Although Indonesia and China are simultaneously grouped in collectivist countries, Mangundjaya (20I3) research at XYZ company with a large sample size found that the stereotypes that emerged about Indonesians were not fully found in the study. This raises interest for researchers to examine subjects on cultures that have been grouped together in collectivist states.

Previously, Jurkin \& Adoric (2008) have conducted a preliminary study observing BJW relation to life satisfaction. The difference between this study and Jurkin \& Adoric (2008) research is in the subject and their research topic. The similarity of this study with Jurkin \& Adoric (2008) lays in extracting data regarding BJW. Additionally, the research subjects in Jurkin \& Adoric (2008) are adult individuals in Croatia. Their research topics are belief in a just world, life satisfaction, and depression. Besides, BJW in this study and Jurkin \& Adoric (2008) research are only exploring Global Belief in Just World (GBJW) and Personal Belief in Just World (PBJW), and both do not explore Unbelief Just World (UBJW).

The researchers in this study decide to conduct the study on the cross-cultural field since preliminary studies show that BJW and cultural influences are interwoven (Thomas \& Mucherah, 2016). In this study, researchers will explore Chinese and Indonesian culture. In Chinese culture, two social contexts, namely family control and acceptance of neighbors, 
affect how Chinese people behave. It includes the initiative of conducting maladaptive behavior is also very much determined by these two social contexts (Jessor, Turbin, Costa, Dong, Zhang, \& Wang, 2003). Parents in China tend to control their children more than parents in Western countries. It has a positive contribution to the social adjustment and academic achievement of Chinese children. Moreover, the second social context is strong neighborhood organizations. It covers strong neighborhood organizations, the long tradition of social organization and social control. In academic life, teenagers in China spend more time in school. For them, a school is seen as a context that can facilitate the sociodemographic development of adolescents as well as cognitive and career development. Schools in China are also a means of forming values, standards, and requirements for the formation of youth behavior. It is because schools are branches of national organizations such as the Communist Youth League that encourage schools to direct and regulate youth behavior.

In relation to this, the concept of happiness in Indonesia must be understood based on the context of the local community (Gularso, Sugito, \& Zamroni, 2019). For example, the concept of happiness in the Malay community develops from the values existing in the Malay community, namely traditional values and religious values (Masyhuri, Subandi, Azhat, \& Suud, 2020). In Indonesia, Indonesian societies are closely attached to the religiosity values, including parenting terms. For Indonesian, religion is a crucial developing component. Islam, as a religion for the majority of Indonesians, teaches its people to live in harmony, respect, and obey older figures (Abubakar, Van de Vijver, Suryani, Handayani, \& Pandia, 20I5). In the context of students, it reveals several findings such as grit, the meaning of life, and life satisfaction among students (Djaling \& Purba, 2019). The results of these studies indicate that the meaning of life partially mediates the relationship between grit and life satisfaction.

Based on the previous explanation, the purpose of this study is to determine the relationship between belief in a just world and life satisfaction among students by comparing the culture of Chinese students to Indonesian students. From this study, the novelty offered is that data collection was carried out in both countries so that the data obtained represents the two countries regarding the BJW and life satisfaction. It is also the originality of this study that in so far cross-cultural research has compared individualist-collectivist 
cultures, but this study compares countries with a collectivist background. The underlying thing is that each culture is unique which will influence the cognitive, affective, and conative of its inhabitants (e.g Kastanakis \& Voyer, 20I4).

\section{Method}

\section{Research Subject}

The characteristics of the subjects in this study are undergraduate students from Indonesia and China, regardless of age and gender. In Indonesia, the data collection process was carried out on paper-based at two campuses in Yogyakarta. Previously, the researchers visited both campuses to apply permits. After the permit was revealed by the authorities at the two campuses, researchers come directly to the research subjects at the time provided by the authorized official. The research subjects were given one booklet containing a willingness sheet to be research subjects and three research scales. In China, the data collection process was carried out by Chinese researchers online. In the online form that was distributed, there was a section to state a willingness to be a research subject.

\section{Questionnaires}

Belief in just world questionnaire consists of two scales:

General belief in a just world. Dalbert, Montada, and Schmitt in 1987 develop a general belief in a just world (Dalbert \& Stoeber, 2006). The GBJW scale consists of six homogeneous items used to measure the belief that the world is generally fair place. The subjects are asked to choose one of six answer choices that moved between "very inappropriate" (I) to "very suitable" (6). The higher the score indicates a stronger BJW belief. The reliability of this scale moves from $r=0.66$ to $r=0.88$ (Wenzel, Schindler, \& Reinhard, 2017). Example of the items in the GBJW Scale are I) I think basically the world is a just place; 2) I am confident that justice always prevails over injustice; 3) I think people try to be fair when making important decisions.

Personal belief in a just world (Dalbert, 1999) consisting of seven items used to measure events experienced by individuals refers to something that is fair or must be experienced. The reliability of this scale moved from $r=0.82$ to $r=0.87$. 
Example of items in the PBJW Scale are I) Overall, events in my life are just; 2) I am usually treated fairly; 3) I think that important decisions that are made concerning me are usually just.

\section{Life Satisfaction}

Life satisfaction scale used in this study is Satisfaction with Life Scale - SWLS (Diener et al., 1985). SWLS consists of five items in order to measure the global measurement of individual satisfaction, without measuring positive and negative effects. SWLS items are designed to measure the life domains of the research subject according to the criteria used in order to achieve the goal of measuring life satisfaction, namely the global measurement of individual life satisfaction (Pavot \& Diener, 1993). The research subject has been asked to choose one of the seven answer choices that moved from Very Suitable (7) to Very Unsuitable (I). The tests were carried out two months after the tools of measurement instrument was tasted for the first time to get a correlation coefficient of 0,82 and an alpha coefficient of 0,87 . In SWLS, the measurement is unidimensional (William, Pavot, \& Diener, 1993). Example of items in the SWLS are I) I am satisfied with my life; 2) If i could live my life over, I would change almost nothing; 3 ) In most ways my life is close to my ideal.

\section{Result}

The description of gender and age from the research subject will be explained in the tables below.

Table I

Subject Age Data

\begin{tabular}{ccccc}
\hline Age & \multicolumn{2}{c}{ Indonesia } & \multicolumn{2}{c}{ China } \\
& Frequency & Percentage & Frequency & Percentage \\
\hline 16 years old & 0 & $0 \%$ & 2 & $1.03 \%$ \\
17 years old & 3 & $2.67 \%$ & 11 & $5.67 \%$ \\
18 years old & 21 & $18.75 \%$ & 50 & $25.77 \%$ \\
19 years old & 35 & $31.25 \%$ & 56 & $28.87 \%$ \\
20 years old & 20 & $17.86 \%$ & 32 & $16.49 \%$ \\
21 years old & 18 & $16.08 \%$ & 16 & $8.25 \%$ \\
22 years old & 9 & $8.04 \%$ & 16 & $8.25 \%$ \\
23 years old & 5 & $4.46 \%$ & 10 & $5.15 \%$ \\
24 years old & 0 & $0 \%$ & 1 & $0.52 \%$ \\
25 years old & 1 & $0.89 \%$ & 0 & $0 \%$ \\
Total & 112 & $100 \%$ & 194 & $100 \%$ \\
\hline
\end{tabular}


From table I above, it can be seen that most of the subjects, both from Indonesia and China, are aged 18-19 years. From table 2 below, it can be seen that the male and female subjects from Indonesia is quite balanced. As for subjects from China, the female subjects was almost three times more than male subjects.

Table 2

Subject Gender Data

\begin{tabular}{ccccc}
\hline Sex & \multicolumn{2}{c}{ Indonesia } & \multicolumn{2}{c}{ China } \\
& Frequency & Percentage & Frequency & Percentage \\
\hline Male & 57 & $50.89 \%$ & 51 & $26.29 \%$ \\
Female & 55 & $49.11 \%$ & 143 & $73.71 \%$ \\
Total & 112 & $100 \%$ & 194 & $100 \%$ \\
\hline
\end{tabular}

Statistic Test

Before calculating the correlation between the variables, the assumptions were tested to determine whether they met the norms of normality and linearity. The assumptions tests were carried out with the help of the SPSS version from windows program.

According to the One Sample Kolmogorov-Smirnov Test table with $p>0,05$, it is said that the data were normal, that the result shows in table 3.

Table 3

Normality Test

\begin{tabular}{cccc}
\hline Country & Variable & P & Interpretation \\
\hline Indonesia & GBJW & 0.016 & Not normal \\
& PBJW & 0.075 & Normal \\
& LS & 0.200 & Normal \\
China & GBJW & 0.002 & Not normal \\
& PBJW & 0.000 & Not normal \\
& LS & 0.020 & Not normal \\
\hline
\end{tabular}

According the ANOVA table with $\mathrm{p}<0.05$, it was said that the data met the linearity assumption, it is obtained as shown in table 4 . 
Table 4

Linearity Test

\begin{tabular}{ccccc}
\hline Country & Variable & $\mathrm{F}$ & $\mathrm{P}$ & Interpretation \\
\hline Indonesia & GBJW*LS & 4.329 & 0.040 & Linear \\
& PBJW*LS & 13.771 & 0.000 & Linear \\
China & GBJW*LS & 32.446 & 0.000 & Linear \\
& PBJW*LS & 49.575 & 0.000 & Linear \\
\hline
\end{tabular}

According the Assumption Test as shown in table 3 and table 4, a correlation test result was carried out in table 5 .

Table 5

Correlation Test

\begin{tabular}{ccccc}
\hline Country & Variable & $\mathrm{r}$ & $\mathrm{P}$ & Interpretation \\
\hline Indonesia & GBJW*LS & 0.187 & 0.024 & Significant \\
& PBJW*LS & 0.330 & 0.000 & Significant \\
China & GBJW*LS & 0.353 & 0.000 & Significant \\
& PBJW*LS & 0.412 & 0.000 & Significant \\
\hline
\end{tabular}

\section{Comparing Test}

Furthermore, a comparing test was performed for each variable. Comparing test results were obtained from the Tests of Between-Subjects Effect table which is summarized in Table 6.

Table 6

Comparing Test

\begin{tabular}{crcccc}
\hline Variable & \multicolumn{2}{c}{ Mean } & $P$ & $\eta^{2}$ & Interpretation \\
& Indonesia & China & & & \\
\hline GBJW & 24.28 & 27.04 & 0.000 & 0.066 & Significant \\
PBJW & 29.93 & 30.86 & 0.152 & 0.007 & $\begin{array}{c}\text { Not } \\
\text { significant }\end{array}$ \\
LS & 19.05 & 20.54 & 0.026 & 0.016 & Significant \\
\hline
\end{tabular}

Based on table 6, there is a significant difference in the level of GBJW in subjects from Indonesia and China $\left(p=0.000, \eta^{2}=0.066\right)$, that subjects come from China have a higher 
GBJW (mean $=27.04)$ than subjects from Indonesia (mean $=24.28)$. In addition, the level of life satisfaction in the two countries also have a significant difference $\left(p=0.026, \eta^{2}=0.016\right)$ that subjects from China having a life satisfaction score (mean $=20.54$ ) that is higher than subjects from Indonesia (mean $=19.05)$. However, there is no difference in the PBJW rates in the two countries $(p=0.152, p>0.005)$.

\section{Discussion}

BJW acts as the conceptual framework which helps individual understanding or views the life events as meaningful and maintain their sense of happiness (Dalbert in Zhang \& Zhang, 2015). Many empirical studies had found that BJW plays a role in creating happiness (Zhang \& Zhang, 20I5). Lai, Bond and Hui (Zhang \& Zhang, 20I5) conducted a longitudinal study and found that negative attitudes toward the environment and human would lead to a lack of social attachment, got a lot of negative feedbacks from environment which lowering the individual satisfaction result. Moreover, Correia, Batistaa and Limaa (Zhang \& Zhang, 20I5) got a result that there were a correlation between BJW and life satisfaction.

Dalbert (2009) summarized his research on various preliminary studies. There were many studies that showed a connection between PBJW (compared to GBJW) and SWB. Moreover, Dalbert (2009) concluded that PBJW was seen as a personal resource that could help individuals to maintain individual welfare from various situations, age levels, both victims and not. By believing that the world is fair, it will encourage individual to be fair toward the others and the world. The individual dynamics who believes in a just world is that if the individual is unstable to solve the problems in real life, the individual will assimilate is experience in his belief in a fair world. By believing that the world is fair, it will elevate individual to have a fair attitude to others and the world. The dynamic that occurs in individual who believes in a just world is if the individual is unstable to solve the problems in real life, the individual will assimilate his experience in his belief in a fair world. Dalbert (2009) also summarized that various previous studies which explain that when individual who could not overcome injustice in a just world; they justify the experience of injustice as a problem caused by themselves; by minimizing the meaning of injustice by avoiding the overly thinking that injustice arises from one's own false, or by forgiving. 
BJW has point of view as coping mechanism (Lerner \& Miller in Oppenheimer, 2006). The explanation from these experts is that BJW has a function as a guard / buffer against stressful conditions. Another expert, Subbotsky (Oppenheimer, 2006), believes that BHW has primitive beliefs that create order in a chaotic environment. In other words, BJW promotes mechanism for individual development.

Dalbert (Oppenheimer, 2006) found the results on his study that from all levels of subject age, PBJW was higher than GBJW. According to his results, (Oppenheimer, 2006) found that started at 12 years old, belief in a fair physical and social world (GBJW) decreased. On the other hand, self-belief that was treated fairly (PBJW) begun to reduce suddenly around the age of 16 .

Related to the culture, it can be concluded that BJW does not relate to culture but it constructed and modified by individual with age (Oppenheimer, 2006). Culture affects individual perception to measure whether in a current situation, individual feels happy or not based on the norms that apply to their culture (Diener, 1984).

The results of the study showed that individual tended to encourage themselves to believe that PBJW was stronger than GBJW and both two terms had different meaning. PBJW was the best predictor of good results (e.g. SWB), when GBJW was the best predictor of harsh social attitude (e.g, Begua \& Muller in Dalbert, 2009). The results in this study indicated that BJW should not be seen as a bipolar construct, but as a two-dimensional construct.

The previous study which was done by Leung Wong, Wong and McBride-Chang, 2010 (Schwarz, Mayer, Trommsdorff, Ben-Arieh, \& Friedlmeier, 20I2) found the importance of positive parent-child relationship on achieving child life satisfaction, in this case the warmth of early adolescent parents in China. Another study was conducted by Leung, McBrideChang and Lai in 2004 (Schwarz et al., 2012) got the result that mother's warmth was associated with the increase life satisfaction of adolescents. Other expert also found that parental acceptance, which came in the form of warmth, support, and a willingness to understand the child, was positively associated with the psychosocial adjustment of children and adolescents (Khaleque \& Rohner, 2020 in Schwarz et al., 2012). In Chinese culture, the 
term filial piety is known. Filial piety is a concept in Confucianism in the form of rules on how to behave and attitude from the younger generation toward the elder generation (Yeh \&Bedford in (Sun, Liu, Huang, \& Qian, 2016). These rules, for example, the younger generation must respect, help, and look after their parents, provide emotional and material support for parents, including preparing for ancestral worship ceremonies (Ho, Xie, Liang \& Zeng, 2012 in Sun et al., 2016). Children who have high belief in filial piety will interact harmoniously and respect their parents; the result is a sense of satisfaction with the life that the child lives. In the collective culture such as Chinese, the harmony relation is the important factor to measure the individual life satisfaction (Raboteg-Saric \& Sakic in Sun et al., 2016).

Most Indonesian families emphasize closeness, harmony, music, achievement, and teamwork - togetherness. It is an obligatory for children to obey their parents and maintain the good name of the family. Father, who plays role as the head of the family, becomes a decision maker in the house. Often, father keeps their distance from their children in daily interactions. In everyday life, mother more interacts with the children and acts as disciplinarian at home (Magnis-Suseno in Abubakar et al., 20I5).

This study is enriched empirical research relate to culture happiness, especially in collective countries such as Indonesia and China. In addition, there are few of studies related to BJW variable in Indonesia which is an added value for this study. However, this study is not inseparable for its lack, for instance this study is lack in deep study related to cross-cultural studies.

\section{Conclusion}

Based on data analysis carried out by the researcher, the conclusions are shown as follows: First, there was a significant positive between global beliefs in just world with the life satisfaction toward the researcher's subjects of Indonesian college students. Second, there was a significant positive between global beliefs in just world with the life satisfaction toward the researcher's subjects of Chinese college students. Third, there was a significant positive between personal beliefs in just world with the life satisfaction toward the researcher's 
subjects of Indonesian college students. Fourth, there was a significant positive between personal beliefs in just world with the life satisfaction toward the researcher's subjects of Chinese college students. Fifth, there were significant differences between global beliefs in just world toward the researcher's subjects of Indonesian college students. Sixth, there were not differences between personal beliefs in just world toward the researcher's subjects of Indonesian college students. Lastly, there were significant differences between life satisfaction in just world toward the researcher's subjects of Indonesian and Chinese college students.

According to the limitations and weaknesses in this study, the researcher gives some suggestions as follow, first, exploring cross culture issues that occur in Indonesian and Chinese college student. Second, enhancing the theories about cross-culture in the discussions of research study. Third, focusing only on the one variable, by providing the social desirability variable in order to measure the faking of research subject.

\section{Acknowledgment}

The researchers would like to thank to the Psychology Study Program, Universitas Islam Indonesia for funding this research.

\section{References}

Abubakar, A., Van de Vijver, F. J. R., Suryani, A. O., Handayani, P., \& Pandia, W. S. (20I5). Perceptions of Parenting Styles and Their Associations with Mental Health and Life Satisfaction Among Urban Indonesian Adolescents. Journal of Child and Family Studies, 24(9), 2680-2692. https://doi.org//0.1007/s I0826-0I4-0070-x

Antaramian, S. P., Huebner, E. S., \& Valois, R. F. (2008). Adolescent life satisfaction. Applied Psychology, 57(SUPPL. I), I I 2-126. https://doi.org/I0. I I I I/j. I464-0597.2008.00357.x

Chang, E. C., Chang, O. D., Li, M., Xi, Z., Liu, Y., Zhang, X., Wang, X., Li, Z., Zhang, M., Zhang, X., \& Chen, X. (2019). Positive emotions, hope, and life satisfaction in Chinese adults: a test of the broaden-and-build model in accounting for subjective well-being in Chinese college students. Journal of Positive Psychology, I4(6), 829-835. https://doi.org// 0.1080/17439760.2019.1579358.

Chu, J. J., Khan, M. H., Jahn, H. J., \& Kraemer, A. (20I5). Only-child status in relation to 
perceived stress and studying-related life satisfaction among university students in China: A comparison with international students. PLoS ONE, IO(I2), I-I8. https://doi.org/I0.137I/journal.pone.0144947

Dalbert, C. (2009). Belief in a Just World Claudia Dalbert. Handbook of Individual Differences in Social Behavior, 288-297.

Dalbert, C., \& Stoeber, J. (2006). The personal belief in a just world and domain-specific beliefs about justice at school and in the family: A longitudinal study with adolescents. International Journal of Behavioral Development, 30(3), 200-207. https://doi.org/ I0.1 I77/0165025406063638

Diener, E. (1984). Subjective well-being. Psychological Bulletin, 95(3).

Diener, E., Emmons, R. A., Larsen, R. J., \& Griffin, S. (1985). The staisfaction with life scale. 49(I), 7I-75. https://doi.org//0.1207/s I5327752jpa490 I

Djaling, K. W., \& Purba, D. E. (2019). Efek mediasi makna hidup pada hubungan antara grit dan kepuasan hidup pada mahasiswa. Jurnal Psikologi Ulayat, 6, I35-149. https://doi.org//0.24854/jpu02019-233

Gularso, D., Sugito, \& Zamroni. (2019). Kawruh pamomong: Children education based on local wisdom in yogyakarta. Cakrawala Pendidikan, 38(2), 343-355. https://doi.org/I0.2183I/cp.v38i2.21556

Jessor, R., Turbin, M. S., Costa, F. M., Dong, Q., Zhang, H., \& Wang, C. (2003). Adolescent problem behavior in china and the united states: a cross-national study of psychosocial protective factors. Journal of Research on Adolescence, 13(3), 329-360. https://doi.org/I0.1 I I I/I532-7795.1303004

Jurkin, M., \& Adoric, V. C. (2008). Belief in a just world and depression. 4th European Conference on Positive Psychology. https://doi.org// 0.2307// 389045

Kastanakis, M. N., \& Voyer, B. G. (20I4). The effect of culture on perception and cognition: A conceptual framework. Journal of Business Research, 67(4), 425-433. https://doi.org/10.1016/j.jbusres.2013.03.028

Kim-Prieto, C., Diener, E., Tamir, M., Scollon, C., \& Diener, M. (2005). Integrating the diverse definitions of happiness: A time-sequential framework of subjective well-being. Journal of Happiness Studies, 6(3), 26I-300. https://doi.org/ I0.1007/s 10902-005-7226-8

Lench, H. C., \& Chang, E. S. (2007). Belief in an unjust world: When beliefs in a just world fail. Journal of Personality Assessment, 89(2), 126-135.

https://doi.org/I0.1080/0022389070I 468477

Lipkus, I. M., Dalbert, C., \& Siegler, I. C. (1996). The importance of distinguishing the belief in a just world for self versus for others: Implications for psychological well-being. Personality and Social Psychology Bulletin, 22(7), 666-677. https://doi.org/I0.1 I77/0I46/67296227002 
Mangundjaya, W. (20I3). Steering the cultural dynamics (Y. Kashima, E. S. Kashima, \& R. Beatson (eds.)). IACCP commitee.

Masyhuri, M., Subandi, S., Azhar, M., \& Suud, F. M. (2020). The concept of happiness for Islamic Community of melayu kampar Riau Indonesia. Journal of Critical Reviews, 7(I2), 833-838. https://doi.org//0.31838/jcr.07.12.147

Oppenheimer, L. (2006). The belief in a just world and subjective perceptions of society: A developmental perspective. Journal of Adolescence, 29(4), 655-669. https://doi.org/10.1016/j.adolescence.2005.08.014

Pavot, W. \&, \& Diener, E. (2008). The satisfaction with life scale and the emerging construct of life satisfaction. Journal of Positive Psychology, 3(2), I37-I 52. https://doi.org//0.1080/17439760701756946

Pavot, William, \& Diener, E. (1993). Review of the satisfaction with life scale psychological assessment. Psychological Assessment, 5(2), 164-I72.

http://link.springer.com/10.1007/978-90-48I-2354-4

Proctor, C., Linley, P. A., \& Maltby, J. (2009). Youth life satisfaction measures: A review. Journal of Positive Psychology, 4(2), I28-I44. https://doi.org/I0.I080/I 74397608026508I6

Schwarz, B., Mayer, B., Trommsdorff, G., Ben-Arieh, A., Friedlmeier, M., Lubiewska, K., Mishra, R., \& Peltzer, K. (20I2). Does the importance of parent and peer relationships for adolescents' life satisfaction vary across cultures? Journal of Early Adolescence, 32(I), 55-80. https://doi.org//0.1 177/027243161/419508

Sun, P., Liu, B., Jiang, H., \& Qian, F. (2016). Filial piety and life satisfaction among chinese students: Relationship harmony as mediator. Social Behavior and Personality, 44(I I), 1927-1936. https://doi.org/10.2224/sbp.2016.44.11.1927

Thomas, K. J., \& Mucherah, W. M. (2016). How fair is my world? Development of just world beliefs among Kenyan students. Journal of Adolescence, 49, 244-253. https://doi.org/10.1016/j.adolescence.2016.03.01 I

Wenzel, K., Schindler, S., \& Reinhard, M. A. (20I7). General belief in a just world is positively associated with dishonest behavior. Frontiers in Psychology, 8(OCT), I-8. https://doi.org/l 0.3389/fpsyg.2017.01770

Zhang, J., Zhao, S., Lester, D., \& Zhou, C. (20I4). Life satisfaction and its correlates among college students in China: A test of social reference theory. Asian Journal of Psychiatry, 10, 17-20. https://doi.org/10.1016/j.ajp.2013.06.014

Zhang, Z., \& Zhang, J. (2015). Belief in a just world mediates the relationship between institutional trust and life satisfaction among the elderly in China. Personality and Individual Differences, 83, I64-169. https://doi.org/I0.1016/j.paid.20I5.04.015 